Comunicación y género

ISSNe: 2605-1982

https://dx.doi.org/10.5209/cgen.66509

\title{
María Egipciaca y Breaking the Waves: la irresistible atracción de la prostituta mártir
}

\author{
Cristina Martínez Istillarte ${ }^{1}$
}

Resumen. La vida de María Egipciaca ha sido por siglos imaginada y diseminada a mano de un notable puñado de hombres, en su mayoría miembros del clero, con propósitos correspondientes. Dentro de dicho corpus literario se evidencia toda una manera de escribir sobre conversiones de mujeres, espacio donde se idealiza el sacrificio corporal femenino y, por ende, promueve imágenes e ideas esencialistas sobre la mujer y/o lo femenino. Este estudio analiza la intertextualidad entre la leyenda de María Egipciaca y el filme Breaking the Waves (1996), del director danés Lars Von Trier, cuya protagonista -aquí se propone- es eco directo de María Egipciaca.

Palabras clave: intertextualidad; género; sacrificio; adaptación; apropiación.

\section{[en] Mary of Egypt and Breaking the Waves: the irresistible attraction of the martyr prostitute}

\begin{abstract}
The life of Maria of Egypt has been for centuries imagined and disseminated by a notable number of men, mostly members of the clergy. Within this literary corpus there is a clear way of writing about women conversions, space where the corporal sacrifice is idealized and, therefore, promotes essentialist images and ideas about women and/or feminity. This article analyzes the intertextuality between the legend of Mary of Egypt and Lars Von Trier's film Breaking the Waves (1996), whose protagonist-herewith proposed-is a contemporary representation of Mary of Egypt.
\end{abstract}

Keywords: Intertextuality; Gender; Sacrifice; Adaptation; Appropriation.

Sumario. 1. Introducción. 2. Estado de la cuestión. 3. Vida de María Egipciaca: la conversión de extrema pecadora a santa intensa. 4. Breaking the waves: Bess McNeil como versión contemporánea de la prostituta mártir en el género cinematográfico. 5. Conclusiones. 6 . Referencias bibliográficas.

Cómo citar: Martínez Istillarte, C. María Egipciaca y Breaking the Waves: la irresistible atracción de la prostituta mártir. Revista Comunicación y género, 2 (2) 2019, 183-191.

\section{Introducción}

Al igual que el caso de San Agustín y de muchas figuras que pueblan la hagiografía católica, la vida del personaje histórico que da punto de partida a la leyenda de María Egipciaca parece ser la conversión de extrema pecadora a santa intensa, salto entre grados máximos que a veces ponen en peligro la verosimilitud del relato. A diferencia de San Agustín, quien escribe su propia autobiografía, Confesiones, la vida de

1 Tulane University (Estados Unidos) 
María Egipciaca, ha sido por siglos imaginada y diseminada a mano de un notable puñado de hombres, en su mayoría miembros del clero, con propósitos correspondientes. Dentro de dicho corpus literario se evidencia toda una manera de escribir sobre conversiones de mujeres, espacio donde se idealiza el sacrificio corporal femenino y, por ende, promueve imágenes e ideas esencialistas sobre la mujer y/o lo femenino.

A modo de adelantar una hipótesis general sobre la vigencia o persistencia de dicha manera de escribir y/o imaginar conversiones femeninas a finales de siglo xx, este estudio analiza la intertextualidad entre la leyenda de María Egipciaca y el filme Breaking the Waves (1996), del director danés Lars Von Trier, cuya protagonista aquí se propone como eco directo de María Egipciaca. Más allá de esta identificación, adelanta el ensayo la hipótesis de que la reproducción de este modelo de escritura y/o representación, en el caso de Breaking the Waves, pone de relieve un cuestionamiento de la misma. Tomo como punto de partida crítica al académico Jack Zipes (1994), quien, sobre otro corpus literario, advierte que la estasis es un modelo poco fiable para entender el funcionamiento de textos canónicos a lo largo del tiempo y espacios culturales y estas otras versiones abren más que cierran posibilidades, "not closure but openness, not recuperation but differentiation, not the establishment of a norm but the questioning of all norms" (Zipes, 1994: 158).

\section{Estado de la cuestión}

El primer autor interesado por la vida de esta pecadora y santa, según establece Gómez Redondo (1998) en Historia de la prosa medieval castellana, fue un tal Sofronio -muerto en el año 638- quien utilizaría esta figura femenina "como exemplum con el que contrarrestar la supuesta perfección a que creía haber llegado el monje Zósimas" (Gómez Redondo, 1998: 1344). Sin embargo, argumenta Redondo, este núcleo significativo de "pecado-redención" es lo que realmente incita el interés de los siguientes recopiladores de la leyenda medieval, lo que resultó en una "abrumadora cantidad de títulos" que acreditan la "irresistible atracción" de un gran público medieval por la figura de María Egipciaca. Es, sin duda, para este autor la dualidad con la que esta figura es concebida, es decir, una mezcla de deseo humano y aspiración religiosa, lo que dio paso a interpretaciones fáciles "con un ser tan quebradizo" que al mismo tiempo "proporcionaba sólidas esperanzas de redención" (1998: 1344). Para Dayle Seidenspinner-Núñez (2008), parte del encanto de la leyenda de Santa María Egipciaca en el imaginario medieval recae en la "juxtaposition of the themes of flamboyant sexuality and extreme asceticism" (Seidenspinner-Núñez, 2008: 239). Además, no solo la literatura se hizo eco de la seductora imagen de la prostituta santa, sino que también el arte y calendarios litúrgicos participaron en el énfasis de esta imagen en el lector medieval. Este mito de la prostituta santa, argumenta Seidenspinner-Núñez, "evolved in early hagiographic legends of St. Mary Magdalene, St. Mary the Egyptian, St. Thais, St. Pelagia, and St. Mary the Harlot and was poeticized and amplified into full-scale romance in the thirteenth-century hagiographic poems" (2008: 244). Los romances en verso, como la versión española Vida de madona Santa María Egipçiaqua y la versión en francés medieval Vie de Sainte Marie L'Egyptienne ayudaron a diseminar y popularizar con gran eficacia "the harlot-saint legend that later versions could circulate in the form of prose abrid- 
gments, reminders to a contemporary audience of a fuller, well known, and muchloved legend" (Seidenspinner-Núñez, 2008: 244).

Así pues, la imagen de mujer que oscila entre tentadora y virgen asceta se popularizó a través de los muchos relatos medievales dando lugar al arquetipo de prostituta arrepentida que representó un paradigma medieval y ocasionó todo un corpus literario y artístico a través de sus principales figuras -María Magdalena y María Egipciaca- que alaba e idealiza el sacrificio femenino dando lugar a la repetición de imágenes e ideas esencialistas sobre las mujeres aún presentes en nuestros días.

\section{Vida de maría egipciaca: la conversión de extrema pecadora a santa intensa}

En la Vida de María Egipciaca es precisamente la libertad de movimiento en las elecciones de la prostituta lo que la lleva a convertirse en mártir y santa. Cuando María Egipciaca deja Alejandría para subirse en un barco camino a Jerusalén ofrece pagar su pasaje mediante intercambios sexuales con la tripulación; una vez abordo no hay hombre que se resista a sus atributos y su hermosura -ni siquiera los peregrinos rumbo a Jerusalén para celebrar la Ascensión de la Virgen-y acaba teniendo relaciones con todos y cada uno de ellos. Es decir, los pecados de María Egipciaca alcanzan el clímax en este viaje que la lleva al punto más cercano antes de iniciar la última travesía de su vida, la peregrinación por el desierto como ermitaña asceta. Una vez en Jerusalén, María Egipciaca inicia su conversión con el primer encuentro espiritual que tiene lugar el día de la festividad de la Ascensión, en la iglesia donde un grupo de ángeles le impide el paso. En ese momento María Egipciaca es consciente de la intensidad/cantidad de sus pecados y se arrepiente, con lo que ofrece una oración ante la imagen de la virgen. La respuesta es entonces "milagrosa" ya que esta escucha una voz celestial que le indica continuar su camino hacia el río Jordán, tomar la comunión en la Iglesia de San Juan y dirigirse al desierto donde acabará sus días. Y es a partir de su llegada al desierto donde María Egipciaca completa su conversión espiritual que va unida a una evidente degradación corporal.

Es aquí útil destacar la importancia y función del desierto, ese espacio donde María Egipciaca se somete a los estragos de una vida ascética y arrepentida desea olvidar su pasado errante y pecaminoso. Como apunta Ernesto Delgado, el desierto es "es el espacio donde se reconstituye María convirtiéndose de una persona sin valor, ni moral ni legalmente, en un ser que goza de la gracia de Dios y la comunión de los santos" (2013: 289). Para Delgado, el desierto se convierte en el lugar donde María Egipciaca y otras ascetas consiguen más libertad de movimiento, en contraste a la que les permiten las normas de su sociedad. Por otro lado, Scarborough indica que el desierto "constituye un elemento desestabilizante del status quo y además, un sitio donde las mujeres, como María de Egipto, pierden los atributos físicos de mujer para convertirse en seres asexuales" (2012: 138). Es decir, en términos más amplios, en el desierto María Egipciaca "desdibuja las fronteras que han sido impuestas en tanto persona social, de modo que [...] deja de estar atada a las limitaciones que la sociedad impone" (Delgado, 2013: 287).

De este modo, la estancia en el desierto cementa la conversión de María Egipciaca, algo que va de la mano del deterioro físico, yuxtaponiéndose así la pureza espiritual con la decrepitud corporal. Se llega así a momento apoteósico, dentro de un espacio igualmente cumbre donde, como bien señala Scarborough, "[María Egip- 
ciaca] anda sobre las mismas aguas del río donde se bautizó Jesús, [...] se transforma en un alma completamente redimida. El agua es el agente purificante y la asociación de María con el río nos recuerda que, después de su dura prueba en el desierto, le han sido perdonados todos sus pecados" (2012: 142). Implícita en dicha exaltación, por supuesto, está el deterioro físico total, lo que sugiere una aparente transacción donde se intercambia salvación espiritual por sacrificio corporal femenino.

\section{Breaking the waves: Bess McNeil como versión contemporánea de la prostituta mártir en el género cinematográfico}

Dentro del amplio abanico de ejemplos contemporáneos donde dicha continuidad de la mujer mártir es evidente y por ello objeto de estudio en este ensayo, destacamos el filme Breaking the Waves (1996) del director y guionista danés Lars Von Trier. Si bien la carrera cinematográfica de Von Trier se caracteriza por una difícil resolución en la interpretación por la peculiaridad de escapar a fijeza o respuesta única, en el caso de Bess McNeil, protagonista femenina, atendemos a una relación directa entre la grandeza de su sacrificio y la salvación y recuperación de Jan, su esposo. De alguna manera resulta evidente que Von Trier se apropia de este planteamiento de la mujer ya popularizado en la Vida de María Egipciaca y otras versiones medievales trasvasándolo al medio contemporáneo de consumo de masas por excelencia.

En ambos relatos, Vida de María Egipciaca y Breaking the Waves, la idealización del sacrificio como devoción absoluta y camino a la salvación -propia y del prójimo- asume la motivación de las acciones de estas dos protagonistas femeninas. Las vidas de María Egipciaca y Bess McNeil se hallan fuertementes marcadas por una simbología común que en ambas obras toma la forma del carácter siempre creciente del pecado, así como la expulsión de la comunidad y/u hogar y, sobre todo, del barco y el agua cuya aparición las precipita a un abismo que marca la consecución del "milagro" o milagros.

Dicha apropiación viene en parte, según el testimonio del propio Von Trier, de un relato infantil: "It was a picture book about a little girl who goes into the forest with some slices of bread and other stuff in her pockets. But at the end of the book, when she's got through the forest, she's standing naked and with nothing left" (Von Trier, en Fernández, 2016: 21). Además de la evidente inspiración folclórica, Von Trier también señala que ve en la historia detrás del cuento -Guldhjerte- una cierta resonancia religiosa, pues la frase con la que se concluye el relato, "But at least, I'm okay", le parecía expresar "the ultimate extremity of the martyr's role" (Von Trier, en Fernández, 2016: 21).

Todo esto, unido al hecho de que Von Trier buscaba dirigir un filme de temática religiosa, convierte Breaking the Waves y específicamente a Bess en una versión contemporánea y cinematográfica de la prostituta mártir. El término apropiación, como argumenta Julie Sanders (2015) en Adaptation and Appropriation, "frequently effects a more decisive journey away from the informing text into a wholly new cultural product and domain, often through the actions of interpolation and critique as much as through the movement from one genre to others" (2015: 35). Así que, de alguna manera, y como se muestra en las palabras de Von Trier, las apropiaciones tienden a tener "a more complicated, intricate and sometimes embedded relationship to their intertexts than a straightforward film version of a canonical or well-known 
text would suggest" (Sanders, 2015: 35-36). En este caso el nuevo producto cultural, Breaking the Waves, no mantiene una relación directa ni aparentemente voluntaria o consciente con la leyenda de María Egipciaca -intertexto propuesto en este estudiosino que se apropia de la figura "general" de la pecadora santa y la explota en este medio perpetuando dicha imagen a la vez que se cuestiona. Dicho de otra manera, y parafraseando a Zipes (1994: 158), sería un error concebir el funcionamiento de textos canónicos como algo estático a lo largo del tiempo; y error más grave aún, el cerrarse a la posibilidad de que alguna nueva versión adelante propósito muy diferente al texto que aparenta recuperar.

En su interpretación más básica, Breaking the Waves presenta una historia de amor incondicional entre Bess y Jan. Por supuesto, nada de esto parece extraordinario hasta que dicho amor, especialmente el que Bess profesa a Jan, es puesto a prueba al sufrir este un accidente que lo deja paralítico y condenado a cama. Si bien este infortunio, por un lado, pone en evidencia la fragilidad del vivir, por otro refleja y ensalza la fuerza y el empoderamiento de Bess como agente con capacidad de cambio en esta marea donde el único timón es su amor por Jan. Bess McNeil pertenece a una hermética comunidad religiosa donde el silenciamiento de la mujer es la norma y parece no ser cuestionado. En cambio, Von Trier utiliza las vicisitudes y dificultades del vivir como fuerza generadora de agencia y voz en nuestra protagonista. Las diversas maneras en las que esta voz comienza a definirse no se corresponden, sin embargo, con el regreso accidentado de Jan, sino que empiezan a pincelarse ya desde las primeras escenas del filme con la decisión de casarse con un "outsider".

Cabe poca duda de estar ante una historia de amor poco tradicional cuando, más adelante en el filme, Bess inicia su unión espiritual con el paralítico Jan por medio de otros hombres -a petición de este- como única vía hacia su salvación; camino que la conduce a la expulsión de su comunidad y a la muerte. Por último, en la partida de Bess, al final del filme, no solo atendemos al "milagro" esperado -Jan sobrevive y vuelve a caminar-, sino que del cielo se advierte el rugido de dos colosales campanas, como en un equitativo intercambio de energías con forma de sonido, de armonía. De esta manera, se puede concluir que la naturaleza subversiva de Bess conforma una especie de catálisis que inspira o inicia la ruptura con la inefable rigidez de su comunidad.

Según la lectura feminista de Makarushka (1998), el filme se basa principalmente en Bess, en su estatus como mujer en una cultura patriarcal y su lucha por ser "buena", lo que la convierte en una suerte de campo de batalla que acaba con su muerte (1998: 5). Si bien la reinterpretación que hace Bess de la bondad y la fe no encaja o, más bien, desafía el paradigma social de su comunidad cuya estructura define a las mujeres como ciudadanos de segunda clase, para Makarushka, considerar a Bess una víctima o una heroína es irrelevante porque lo que Breaking the Waves consigue es denunciar las actitudes religiosas y culturales que "condemn women to the bondage of some stereotypes of normal feminity" (Makarushka, 1998: 4-5). La posición de Bess es una muy conflictiva, pues su elección de prostituirse para salvar a Jan subraya la escasez de "culturally sanctioned positive paradigms available to women", mientras que por otro lado pone de relieve una de las cuestiones que más preocupa a las mujeres: "is it possible to be 'good' outside of the culturally constructed paradigms that [...] demean and constrain them?" (Makarushka, 1998: 3).

Como se podrá observar, el filme presenta un cuadro desestabilizador, precisamente porque suscita toda una serie de preguntas lógicas sobre definiciones básicas, 
como el ser una buena persona. Si bien Breaking the Waves articula preocupaciones ideológicas y culturales, entre ellas cuestiones de género, el filme debe la precisión con la cual logra dicho objetivo a la apropiación de la figura de la prostituta mártir; por medio de este modelo de mujer, que conlleva efectos innegablemente destructivos, se llega a una punzante crítica cultural que roza la ironía y la parodia en la forma de dos colosales campanas cuya aparición se sincroniza con la ascensión del cielo de Bess al final de la película.

Como en el caso de María Egipciaca, el escenario donde acontece la vida de Bess informa de su capacidad de relatar con imágenes la presunción que se confirma durante la trama: el paisaje frío y austero del norte de Escocia le sirve como símbolo de las rígidas normas morales de la iglesia y el resto de los hombres que la conforman. De esta manera, cuando Bess no se limita a las reglas de la comunidad, bien es amenazada con la hospitalización (a través de las continuas referencias su falta de estabilidad mental), bien con la medicación; maneras en las que se pretende controlar las decisiones que va tomando a lo largo del filme, cuya ejecución, por supuesto, pone en juego el status quo y la estabilidad de su comunidad en cuanto al claro y limitado rol de las mujeres. Bess se encuentra en una encrucijada ya que, si bien desea seguir perteneciendo a su comunidad y ser buena bajo los términos de esta, el inevitable contexto en el que se halla la "obliga" a crear sus propios términos, lo que justifica la expulsión de su comunidad y seno familiar.

Dentro de estos términos, destaca, sin lugar a duda, su elección de hablar con Dios, lo que añade dificultad a su particular manera de entender la naturaleza de ser y actuar como buena mujer, es decir, de ajustarse a los cánones que ella debe ocupar en dicho entorno, así como su manera de entender y relacionarse con la fe. A través de estas conversaciones en las que Bess da voz a ambos - su dios y ella misma- se informa al espectador de la complejidad de la situación: por un lado, el cumplimiento de los valores y moral tradicionales; por el otro, la libertad y deseo de actuar fuera dichos confines. No solo este es un acto más que cuestionable dentro de la estructura patriarcal de su comunidad, sino que además Von Trier lo intensifica al localizar estos diálogos con Dios en la iglesia de la que más adelante será expulsada. Siendo la mujer parte de una comunidad donde su silenciamiento social es la norma, Bess desafía y desestabiliza el orden patriarcal de la misma.

En dichas conversaciones, Dios le dice a Bess que soporte la soledad mientras que por otro lado le dice que pruebe su amor por Jan; y para probar este amor, Bess acaba prostituyéndose. El camino de la prostitución/salvación es uno arduo sembrado de dudas y miedo a pecar que la protagonista trata de resolver en estas conversaciones. Cuando nuestra protagonista se confiesa, "Dear God, I have sinned", la respuesta de Dios/Bess consiste en el ejemplo de María Magdalena, quien fuera una de sus más queridas. Esta respuesta es una clara evidencia del papel de Bess en este relato de apropiación/adaptación, Breaking the Waves, de la leyenda o arquetipo de pecadora mártir.

La palabra de Dios nos llega a en este filme por dos vías: los ancianos patriarcas de la Iglesia y la propia Bess. No es casualidad, entonces, que estas dos vías no se usen para complementarse en una fe única, sino más bien para excluirse, para oponerse y dejar que el espectador -si es posible acaso- decida con qué camino, vía y desenlace identificarse o, al menos, empatizar. Al transgredir Bess la norma cultural de chica "buena", siempre según los parámetros establecidos por dicha comunidad, esta pasa directamente a desempeñar el rol de chica "mala", único espacio disponi- 
ble en la cultura patriarcal que Bess puede ocupar y en el que puede operar a partir de ese momento. Así, este deseo de Bess por ser buena, por probar la devoción y amor incondicional por Jan a pesar de las consecuencias, se conforma a través de un complejo entramado que no se ajusta a la capacidad interpretativa del marco dualista chica "buena/mala". Al final, lo que importa en Breaking the Waves no es llegar a una conclusión de si Bess es o no es "buena", sino que se subraya la naturaleza de su bondad versus las normas estancadas de su comunidad, es decir, "if the 'good' is a static moral category that assumes compliance, goodness is dynamic, transgressing, and, therefore, dangerous" (Makarushka, 1998: 22).

Al final de la película, cuando se asoman las colosales campanas en el cielo, justo después de tirar las cenizas de Bess al mar, se ironiza o se juega con esta inesperada aparición a modo confirmación del milagro, de estabilización del orden y de las fuerzas competentes entre las normas de dentro y fuera de la comunidad. Antes ambas silenciadas, primero Bess rompe con ese silencio desencadenando la salvación de Jan y la aparición y melodía de las campanas nunca presentes durante la película; lo que sugiere que, si las mujeres y las campanas se silencian en vida, estas rompen el silencio en muerte o en camino hacia ella. Con esta imagen final, Breaking the Waves igualmente parece advertir sobre asociaciones fáciles y comunes entre el autosacrificio y lo femenino en el entorno histórico-cultural del filme. Si bien, y como señala Paula Quigley, "in our profoundly gendered social system governed by a principle of quid pro quo, the 'feminine' scenario of self-sacrifice is naturalized and idealized on the screen in the image of the suffering women" (2012: 167), con la figura de Bess se lleva este sacrificio al extremo, y esto desconcierta dicha relación entre sacrificio y género femenino.

\section{Conclusiones}

Como se menciona al inicio de este estudio, la vida de María Egipciaca ha sido por siglos imaginada y diseminada a mano de un notable puñado de hombres, en su mayoría miembros del clero. Dentro de este corpus literario, se evidencia toda una manera de escribir sobre conversiones de mujeres, espacio donde se idealiza el sacrificio corporal femenino y se promueven imágenes e ideas esencialistas sobre la mujer y/o lo femenino. La vigencia o persistencia de dicha manera de escribir e imaginar conversiones femeninas a finales de siglo Xx, se observa por medio de la intertextualidad entre la leyenda de María Egipciaca y el filme Breaking the Waves (1996), del director danés Lars Von Trier, cuya protagonista, como se ha demostrado, es eco directo de María Egipciaca. Más allá de esta identificación, se concluye que la reproducción de este modelo de escritura o representación, en el caso de Breaking the Waves, pone de relieve un cuestionamiento de esta. Tomando la teoría de Jack Zipes (1994) sobre el funcionamiento de textos canónicos a lo largo del tiempo de espacios culturales, se demuestra que la falta de "estasis" sobre la que Zipes nos advierte es precisamente lo que abre posibilidades a otras versiones de la leyenda que la convierte, en este caso, no en una recuperación, sino en una diferenciación que cuestiona las normas previamente establecidas.

De esta manera, se puede concluir que la naturaleza subversiva tanto de Bess como de María Egipciaca conforma una especie de catálisis que inspira o inicia la ruptura con su comunidad. En la vida de ambas, esta suerte de exilio desencadena un peregrinaje y sacrificio que las arrastra a la muerte, salvación y elevación de su 
figura. Si bien en la Vida de María Egipciaca esto se consigue mediante el contraste de la exageración de la lujuria y el placer sexual con sus correspondientes 47 años de vida ascética en el desierto, en el caso de Bess McNeil son las vicisitudes y las dificultades del vivir, y en especial el accidente de Jan, la fuerza generadora de agencia y voz en dicha protagonista. Asimismo, la lujuria y la actividad sexual de ambas cumplen propósitos distintos en cada una de las versiones: mientras que en la Vida de María Egipciaca estas sirven como canal mediante el cual llegar al clímax de una vida de pecadora y que, por tanto, necesita ser redimida, en Breaking the Waves Bess McNeil se inicia en una actividad sexual atípica con el fin de salvar a su esposo y que culmina con su muerte.

La narrativa de Lars Von Trier incluye e informa de preocupaciones ideológicas y culturales apropiándose de la figura de la prostituta mártir con el fin de usar este modelo de mujer como crítica cultural y sus efectos destructivos, aspectos y contradicciones aparentemente silenciados dentro del corpus literario encabezado por María Egipciaca y María Magdalena. Como argumenta Julie Sanders (2015) en Adaptation and Appropriation, el término apropiación con frecuencia se aleja del texto informante y se convierte en un producto cultural totalmente nuevo a menudo tanto mediante la adición y crítica como mediante transferencia de un género a otro, haciendo que la apropiación de la figura de María Egipciaca por parte de Von Trier en Breaking the Waves se base en una relación más complicada e intrincada con su intertexto. En este caso el nuevo producto cultural, Breaking the Waves, no mantiene una relación directa ni aparentemente voluntaria o consciente con la leyenda de María Egipciaca, sino que se apropia de la figura de la pecadora santa y la explota en este medio perpetuando dicha imagen a la vez que se cuestiona.

El filme se enfoca en Bess y su estatus como mujer en una cultura patriarcal, así como su lucha por ser "buena"; circunstancias que la conducen a su propia muerte. Si bien la reinterpretación que hace Bess de la bondad desafía el paradigma social de su comunidad cuya estructura define a la mujer como ciudadano de segunda clase, considerar a Bess una víctima o una heroína es irrelevante porque lo que Breaking the Waves consigue es denunciar las actitudes religiosas y culturales que condenan a las mujeres a servir ciertos estereotipos de feminidad aceptables. De manera que la posición de Bess resulta muy conflictiva, ya que su elección de prostituirse para Salvar a Jan se hace eco de la escasez de paradigmas positivos disponibles para las mujeres. Así pues, el filme presenta un cuadro desestabilizador al suscitar toda una serie de preguntas lógicas sobre definiciones básicas, como el ser una buena persona. Si bien Breaking the Waves articula preocupaciones ideológicas y culturales, entre ellas cuestiones de género, el filme debe la precisión con la cual logra dicho objetivo a la apropiación de la figura de la prostituta mártir; por medio de este modelo de mujer, que conlleva efectos innegablemente destructivos, se llega a una punzante crítica cultural. Con la figura de Bess se lleva este sacrificio al extremo, y esto desconcierta dicha relación entre sacrificio y género femenino.

Como indica Sanders (2015), las adaptaciones y las apropiaciones, ya sean precuelas, secuelas, extensiones, amplificaciones u otras alternativas, a menudo subrayan vacíos desconcertantes, ausencias y silencios en el original. Muchas apropiaciones, como resultado, profundizan en lo político y lo literario al dar voz a personajes o eventos que habían sido oprimidos o reprimidos en el original. Y la relación entre Breaking the Waves y el corpus literario al cual pertenece María Egipciaca es un buen ejemplo, como se demuestra en este análisis comparativo. 


\section{Referencias bibliográficas}

Delgado, E. (2013) “Ascetas y penitentes en el discurso de los Padres de la Iglesia: hacia una revisión histórica del modelo hagiográfico de la leyenda de Santa María Egipcíaca en la Alta Edad Media" en Romance Quarterly, 50, (4), pp. 281-301.

Fernandez, I. (2016) "In the Kingdom of Men: Love, Faith and Spirituality in von Trier's Breaking the Waves" Journal of Religion \& Film, 25, (1), pp. 1-45.

Gómez Redondo, F. (1998) Historia de la prosa medieval castellana. Madrid, Cátedra, Crítica y Estudios Literarios.

Makarushka, I. (1998) “Transgressing Goodness in Breaking the Waves" en Journal of Religion and Film, 2, (1), pp. 1-38.

Quigley, P. (2012) “The Spectacle of Suffering: The 'Woman's Film' and Lars Von Trier" en Studies in European Cinema, 9, (2-3), pp. 155-168.

Sanders, J. (2015) Adaptation and Appropriation. Londres, Routledge.

Scarborough, C. L. (2012) "El desierto como sitio de reconciliación en la Vida de Santa María Egipciaca", en Botta, P. (coord.), Rumbos del hispanismo en el umbral del cincuentenario de la AIH. Roma, Bagatto Libri Disponible en: https://cvc.cervantes.es/literatura/aih/ pdf/17/aih_17_2_017.pdf.

Seidenspinner-Núñez, D. (2008) "Santa María Egipçiaca (thirteenth-fourteenth centuries)" en Greenia, G. D. y F. Domínguez (eds,), Castilian Writers, 1200-1400. Vol. 337. Detroit (Michigan), Thomson Gale.

Zipes, J. (1994) Fairy Tales as Myth / Myth as Fairy Tale. Lexington, The University Press of Kentucky. 